\title{
Aunque tenga que morir por mis ideas. Conjeturas contemporáneas: Carlo Ginzburg y su posible relación intelectual con Joseph Roth
}

\author{
Olaya Sanfuentes \\ Instituto de Historia \\ Pontificia Universidad Católica de Chile
}

Creo que Carlo Ginzburg leyó a Joseph Roth. Lo que estoy suponiendo no es tan descabellado si pensamos que el primero, el célebre historiador italiano, es un intelectual erudito, muy imaginativo y creativo que tiene que haber leído al que considero uno de los mejores escritores del siglo XX. Si desde este rincón del planeta (Santiago de Chile) hay quienes leemos a Joseph Roth, en Europa muchos más lo habrán leído y habrán visto representados sus sentimientos, experiencias y aprehensiones hacia una Europa herida tras los estragos de la guerra, de la Primera Guerra Mundial. Y en términos formales, si Carlo Ginzburg ha sido siempre un defensor de la buena narración ${ }^{1}$-aspecto que cuida mucho en sus obras-, con más razón tiene que haber leído la bella y simple prosa de Joseph Roth.

Cuando pienso en Ginzburg leyendo a Roth no puedo sino imaginármelo leyendo El Leviatán, una novela que describe el mundo mental y material de un vendedor de corales en la Rusia profunda. Un vendedor judío que tiene unas ideas cosmogónicas surgidas de su propio mundo material y espiritual que no pueden sino hacerme pensar en aquella materialidad que inspiraría a Menocchio, protagonista de El queso y los gusanos de Ginzburg, en sus figuras e imágenes que describen su forma de concebir este mundo y el otro.

Quizás me equivoco y Carlo Ginzburg no leyó nunca a Joseph Roth, pero hay ciertos aspectos que se muestran muy elocuentes para conjeturar una relación intelectual.

Hablemos primero, por orden cronológico, de Joseph Roth (1894-1939) y su Leviatán, que fue publicado en forma póstuma en 1939, cuando estalla la Segunda Guerra Mundial y nace Carlo Ginzburg. Desde Roth es que luego introduciremos a Ginzburg.

\footnotetext{
1 Hay un grupo de historiadores contemporáneos a quienes les interesa sobremanera la buena escritura a la hora de hacer historia, defendiendo un género entre la historia y la literatura para comunicar sus trabajos y para dar cuenta de los múltiples puntos de vista que utilizan para mostrar su problema de interés. Entre estos historiadores y sus obras, además del célebre ejemplo de Carlo Ginzburg y su obra, es posible destacar a Natalie Zemon Davis y su Regreso de Martin Guerre (1983) y Emmanuel Le Roy Ladurie, quien en su obra Montaillou (1975), describe la vida cotidiana de un pueblo pirenaico.
} 


\section{Mundos que se derrumban y desintegran}

Casi toda la producción literaria de Joseph Roth trata del período de quiebre que le tocó vivir en carne propia. La caída del Imperio Austrohúngaro y los derroteros de algunos judíos tras la desaparición de ciertas ciudades del imperio son tópicos que se repiten en su producción literaria. Sus personajes ficticios se mueven en un escenario que muestra el cambio desde un estado plurinacional y multiétnico a una situación de incertidumbres, de cambios en las reglas del juego, de miedos y de pérdidas. Muchas de sus obras pueden leerse en esa clave. La Marcha de Radezky, por ejemplo, es la historia de la familia Trotta y la desintegración paulatina del imperio. Esta historia se retoma luego en la obra La cripta de los capuchinos, que relata la vida en la ciudad de Viena en los albores de la Primera Guerra Mundial. El protagonista de esta obra -un joven Trotta- se revela como la encarnación de un mundo en declive.

En El Leviatán, por su parte, se muestra el mundo simple y auténtico del vendedor de corales Nissen Piczenik, que se desintegra con la venida del vendedor de corales falsos, representando el advenimiento de un nuevo ciclo, la llegada del capitalismo, según algunos intérpretes de la obra. Por su parte, el Menocchio de Ginzburg también es un personaje -esta vez histórico-, que vive un período de quiebres. El que trae consigo la Reforma protestante y la consiguiente reacción católica -la Contrarreforma- frente a cualquier manifestación que oliera a herejía. Se reproducen también el miedo y las incertidumbres y, como nos ilustra Ginzburg, "se inicia una época altamente caracterizada por la rigidez jerárquica, el adoctrinamiento paternalista de las masas, la erradicación de la cultura popular, la marginación más o menos violenta de las minorías y los grupos disidentes"(Ginzburg El queso 13).

En ambas épocas se pierde el sentido de unidad europea, aquella unidad que siempre ha sido ansiada y que, por diversas razones cuando se ha conseguido medianamente, se ha roto en forma violenta y traumática. Estas pérdidas de unidad pueden ser de diferente índole. La de Roth es la pérdida de la diversidad cultural en la figura aglutinadora del imperio; la posibilidad real y efectiva de los judíos incorporados en un sistema. El derrumbamiento de esa unidad imperial deja "huérfano y lacerado al hombre contemporáneo en la soledad provocada por su carencia de raíces", dice el escritor Claudio Magris (18). Para Magris (quien, coincidentemente, también nació en 1939), Roth vive la caída del imperio como el fin de la tradición y el comienzo de lo moderno, entendido esto como un proceso de atomización y secularización (47).

Estas frases describen muy bien lo que sintiera también Stefan Zweig, otro intelectual judío de esa época y muy amigo de Joseph Roth (Zweig y Roth). En su novela autobiográfica El mundo de ayer, Zweig repara en los defectos y cualidades de la sociedad que ha desaparecido, un pasado que revive con nostalgia al presenciar su desmoronamiento. Al mismo tiempo, vive con dolor y desesperanza la pérdida de fe en el ser humano que se evidencia en la Primera Guerra Mundial. En resumen, la de Zweig es una 
obra que cuenta el fracaso de la unidad espiritual de Europa frente al patriotismo exacerbado de unos, que llevan a todos a la guerra.

Carlo Ginzburg nace en 1939, por lo que es bastante probable que en su juventud haya leído a Roth. Por otra parte, ambos venían de familias judías y experimentaron el exilio. No es de extrañar, entonces, que un italiano de tradición judía haya leído a otro judío que otorga voz a muchos europeos que fueron víctimas de la guerra. Al menos por empatía biográfica, pienso que Ginzburg debe de haber leído a Roth. Lo de la empatía "con raíces biográficas" ya ha sido propuesto por Michelle Evans Restrepo para comparar El queso y los gusanos con la obra de Giovanni Levi La herencia inmaterial. Evans hace hablar a ambos autores, quienes declaran que su condición de judíos, su exilio y sus opciones políticas de izquierda habrían determinado sus elecciones y formas de acercarse a aquellos grupos e individuos perseguidos de la historia (105-129). Tanto Ginzburg como Levi (quien también nace en 1939) explicitan la relación directa entre sus biografías y sus elecciones. "Conservé un recuerdo muy nítido de la persecución sufrida (...) la idea de trabajar con marginales, con herejes, podía estar ligada al hecho de yo ser judío", comentaba el primero. "Creo que pertenecer a un grupo de minorías es una cosa muy útil para ponerse problemas, para afrontar el mundo desde una perspectiva en parte victimista y en parte narcisista", explicaba el segundo (Ibíd.).

Carlo Ginzburg, por su parte, ha reflexionado acerca de lo que significa para él ser judío, en una reflexión madura y retrospectiva en que se plantea en qué minuto se dio cuenta de su identidad judía. Para él, el tema de la identidad es uno de carácter dinámico. En una entrevista que se le hiciera en la Public Library de Nueva York, Carlo Ginzburg habló de lo que significa "devenir" judío habiendo nacido en un país católico como Italia. Para él, ser judío es, en gran parte, producto de ser perseguido (Stocke). Y es que, efectivamente, la vida de Ginzburg está marcada por la persecución. Su padre, el filólogo Leone Ginzburg, fue encarcelado por no jurar lealtad al régimen fascista y murió luego en la cárcel, víctima de la persecución antijudía y política. Meses más tarde la abuela de Carlo, frente a la inminencia de los acontecimientos políticos de Italia, le diría que si alguien le preguntaba cuál era su nombre que dijera que se llamaba Carlo Tanzi. Años después, Carlo se daría cuenta que Tanzi era el nombre de su padre y que era un nombre no judío. "Retrospectivamente, me doy cuenta de que fue en ese preciso momento que devine judío", diría años después (Ibíd.). Y de ahí en adelante, entonces, decidió que sería historiador para dar voz a los perseguidos. No le interesaba tanto la persecución, como la víctima. Él mismo nos relata que cuando tenía veinte años y estaba en la biblioteca de la Scuola Normale Superiore di Pisa, cuando súbitamente decidió tres cosas: que quería ser historiador, que quería estudiar los procesos de brujería y que lo que le interesaba no era la persecución sino los perseguidos (Ginzburg "Some queries"). Como consecuencia de estas decisiones tempranas es que nos proporciona la vida del molinero del Friuli Domenico Scandella, conocido en su época como Menocchio. Por su parte, de Joseph Roth se ha dicho que "entiende efectivamente la historia como historia de los vencidos y la representación histórica como alegoría de un misterio doloroso que hace de ella un via crucis" (Magris 85). 


\section{Intentos de reordenar el mundo}

En su Leviatán, Joseph Roth parte de un mundo ordenado donde las cosas funcionan y tienen una cierta armonía hasta que sobreviene el caos. No podemos sino leer esta novela como la experiencia personal del propio autor y como el sentimiento de una colectividad europea y judía, que estaba incorporada en la sociedad europea de fines del siglo XIX hasta que cae el Imperio Austrohúngaro y sobreviene la Primera Guerra Mundial. La nostalgia existencial que el protagonista de la novela siente por el mar, puede interpretarse como una añoranza del mundo en épocas de los Austria; mundo que se ha ido para siempre y que él imaginaba abierto y tolerante. El mundo mejor y perfecto, utópico, si se quiere, lo pone Roth en el pasado.

Menocchio, en cambio, es un personaje que, ante el caos ya existente traído por la supuesta pérdida de la unidad cristiana tras la Reforma protestante, intenta con sus teorías establecer un orden universal, intentando unir lo que se ha separado. El mundo no anda bien para Menocchio, pero en vez de buscar un mundo mejor en el pasado, él intenta reflexionar respecto de las posibilidades de mejorar el propio. Lector de la obra de sir John Mandeville, su mente estaba poblada de imágenes de ínsulas habitadas por pueblos con costumbres diferentes, lo que incidió en el desarrollo, en Menocchio, de un espíritu relativista frente a las costumbres y las leyes de su época. Su utopía es fruto de un enaltecimiento de un orden social de religiosidad sencilla, tolerante con todos los credos y enfrentada a los privilegios del clero; él se consolida como el heraldo de un mundo nuevo, creado tras las escisión europea de las ideas hegemónicas de las clases dominantes y la de raíz popular medievalrenacentista (Burucua 100). La secuencia de sus disquisiciones parte de un mundo imperfecto que debiera perfeccionarse (Ginzburg, El queso 160). El vendedor de corales, en cambio, refleja la creencia de un mundo perfecto que luego se corrompió y ahora espera la venida del Mesías.

\section{Individuos en un mundo de clases populares}

Las obras de Ginzburg y de Roth, desde la historiografía uno y desde la novela el otro, pretenden, por medio de sus protagonistas, ser representativas tanto de un tipo humano como de la relación entre estos personajes singulares y un proceso histórico más amplio que los contextualiza. El personaje histórico de Menocchio y el novelesco surgido de la pluma de Roth son ambos representantes de las clases populares de una Europa profunda en dos períodos históricos diferentes. A lo largo de la vida y las ideas del molinero podemos extrapolar muchas de las características de las clases subalternas del siglo XVI europeo, ejercicio que también podemos realizar en el caso del vendedor de corales de un siglo XX sin mayores precisiones cronológicas (Roth 1). Sus microhistorias al mismo tiempo, proporcionan puertas de entrada y de salida a las historias más macro, aquellas que pintan la historia europea de Reforma e Inquisición en el siglo XVI y desmoronamiento del imperio a comienzos del siglo XX.

Ambos personajes son representativos, cada uno en su época pero ambos en Europa, de las clases populares o subalternas. Para definir a este grupo social y sus características, Ginzburg habla de una etnología europea, del 
folclore o tradiciones populares. Tanto el ucraniano vendedor de corales como Menocchio son hombres comunes y corrientes que viven en el completo anonimato y se ganan la vida con su oficio. No obstante, de alguna forma son también personas excepcionales, porque el pueblo repara en ellos. Se podría decir que son "normales excepcionales" (Ginzburg "Microhistoria" 41)2. Roth tiene varias novelas en que adjetiva esta condición ordinaria de sus personajes. En Job, comienza su relato situándonos e introduciendo a los personajes: "Hace muchos años vivía en Zuchnow un hombre llamado Mendel Singer. Era piadoso, temeroso de Dios y muy sencillo: un judío común y corriente, que ejercía la modesta profesión de maestro" (Roth Job). No obstante, merece ser el protagonista de la historia, la que lo convertirá en un ser único.

Ambos personajes -el de ficción y el histórico- nos ayudan a adentrarnos en las relaciones sociales de unidades pequeñas como la familia y el pueblo, mostrando por medio de círculos concéntricos, su rol social en el lugar donde viven y las eventuales concatenaciones con los mundos circundantes. Esto, a pesar de la supuesta excepcionalidad del caso de Menocchio, como se ha argumentado de parte de algunos. A partir de ciertas pistas de personajes aparentemente insignificantes, se pueden conjeturar e inferir características más generales. Un documento, una localidad o un personaje pueden hablarnos de una época y una zona, ya que el conocimiento histórico es uno indirecto, indiciario y conjetural (Jiménez; Ginzburg "Raíces").

Quizás uno podría tentar de hacer un modelo socioantropológico para comprender estas relaciones interpersonales y este mundo de personajes subalternos que logran salir del anonimato y dejar huellas de sus naturalezas y fisonomía para la posteridad: son apegados al terruño, relevan la importancia de la cotidianeidad, así como las relaciones de intercambio, los chismes y los rumores. El contexto de la comunidad y sus relaciones, entonces, puede verse tanto como un espacio donde la anormalidad es posible, una estructura social pequeña que logra hacer eco en su mundo contemporáneo y a posteriori o bien como un escenario representativo de la cultura popular.

\section{Un mundo determinado por la materialidad}

Los personajes de los mundos de Roth y de Ginzburg no son de renombre ni han heredado nada, sino que todo lo que son y lo poco que tienen lo deben a su trabajo físico, manual, aquel que no pueden dejar de realizar porque de él depende totalmente su subsistencia. El vendedor de corales mira, toca, agrupa y clasifica sus corales. Contrata mujeres para que los hilen y armen collares. El molinero carga la harina, utiliza sus herramientas, toca el trigo. Ambos se relacionan con la materialidad de las cosas, con los objetos que comercian, con las herramientas que modifican sus materias primas, con las manos de aquellos que reciben la mercancía, con el dinero del pago o las especies del trueque. Estos hombres parecieran tener preocupaciones básicas y solamente materiales, o relacionarse con un materialismo campesino subterráneo (Anderson 191). Como deben procurarse el sustento diario, pareciera importarles solamente tener algo con qué llenar el estómago, un lugar donde

2 El término es de Edorado Grendi, citado por Carlo Ginzburg. 
dormir y lo mínimo para vestir a sus familias. Pero en el contacto diario con la materia, son testigos de los cambios que experimentan los materiales en su exposición al frío, al calor, la humedad y otras condiciones, así como los cambios que sufren con el paso del tiempo. Sus observaciones les permiten teorizar acerca de realidades externas, reflexiones que, finalmente, marcarán sus destinos. "Yo creo que no se puede hacer ninguna cosa sin materia, y tampoco Dios habría podido hacer cosa alguna con materia", argumentaba el molinero frente al inquisidor (Ginzburg El queso 147).

El vendedor de corales y Menocchio tienen sus ideas personales y propias respecto del mundo y su funcionamiento. Una de las características comunes de estos dos personajes es el animismo que inunda sus cabezas como forma de entender el funcionamiento del mundo circundante. A pesar de todos los siglos que separan a estos personajes, ellos son capaces de representar esa forma de instalarse en el mundo. Forma que es capaz de ver vida en todos aquellos elementos materiales significativos que conforman su mundo cotidiano. La creencia en fuerzas superiores y en la energía y poder de los objetos del entorno, constituye una manera de sacralizar la experiencia ahí donde los elementos del entorno parecen inertes. Esto es lo que lleva a ciertas sociedades a pensar que animales, plantas y objetos tendrían un alma equiparable a la de las personas, trascendiendo lo temporal y terrenal. Tanto Menocchio como el vendedor de corales otorgan a ciertos elementos de su vida cotidiana, un simbolismo que deriva en animismo y que se intuye y construye a partir del contexto social, cultural y material que lo delimita. Para Nissen Piczenik los corales seguían viviendo aún después de ser "serrados, tallados, pulidos, clasificados y ensartados. Y tal vez tenía razón. Porque veía con sus propios ojos cómo sus rojizas sartas de corales comenzaban a palidecer poco a poco en el pecho de las mujeres enfermas o enfermizas, pero conservaban su esplendor en el de las mujeres sanas" (Roth Leviatán 10).

Menocchio ve a Dios en todas las cosas materiales y más específico aún, observa los efectos del tiempo y el ambiente sobre la materia del queso. Presencia el nacimiento de gusanos en el queso putrefacto, lo que le permite explicar el nacimiento de los seres vivos y de los ángeles. Es una cosmogonía esencialmente materialista y casi científica, basada en la observación y registro de los fenómenos (Ginzburg El queso 43) ${ }^{3}$. Y es que finalmente, lo que otorga estatus de verdadero en este mundo es lo natural. En el caso del vendedor de corales el mar es lo único verdadero. En el de Menocchio, el queso y sus gusanos. Para el comerciante de corales es en el origen como metáfora de la pureza donde los seres no están corrompidos aún. En el

\footnotetext{
3 «Yo he dicho que por lo que yo pienso y creo, todo era un caos, es decir, tierra, aire, agua y fuego juntos; y aquel volumen poco a poco formó una masa, como se hace el queso con la leche y en él se forman gusanos, y estos fueron los ángeles; y la santísima majestad quiso que aquello fuese Dios y los ángeles; y entre aquel número de ángeles también estaba Dios creado también él de aquella masa y al mismo tiempo, y fue hecho señor con cuatro capitanes, Luzbel, Miguel, Gabriel y Rafael. Aquel Luzbel quiso hacerse señor comparándose al rey, que era la majestad de Dios, y por su soberbia Dios mandó que fuera echado del cielo con todos sus órdenes y compañía; y así Dios hizo después a Adán y Eva, y al pueblo, en gran multitud, para llenar los sitios de los ángeles echados. Y como dicha multitud no cumplía los mandamientos de Dios, mandó a su hijo, al que prendieron los judíos y fue crucificado».
} 
caso de Menocchio, es en el futuro ordenado donde está la solución al caos contemporáneo.

Menocchio dice que el aire es Dios y que la tierra es nuestra madre. El vendedor de corales observa vida en los corales, criaturas provenientes del Leviatán, el gran pez original. El comerciante manipula con cariño sus corales y cree que son capaces de sanar a las mujeres que los llevan puestos en el cuello. Cuando decide ir a conocer el mar para verificar sus teorías acerca del Leviatán, no está haciendo otra cosa que buscar la observación propia del método científico.

Para poder crear estas ideas en su mente, tanto Menocchio como el vendedor de corales han establecido procesos de apropiación de las ideas canónicas o circulantes en su época y las han hecho suyas según sus propias circunstancias y adecuando los conceptos que ellos comprenden desde sus biografías, sus oficios y sus realidades particulares. Hay libros e ideas contenidas en estos libros que ayudan a configurar los mundos mentales de nuestros personajes y las teorías que elaborarían para conocer y explicar el mundo. El vendedor de corales, en su calidad de judío, tuvo contacto con las historias bíblicas, concretamente nos consta su conocimiento de la historia del Leviatán. El libro de Job, que es la historia del justo que sufre injustamente pretende dejar la lección de que hay que mantener la fe incluso en los momentos más penosos y en las circunstancias más injustas. Algo de esto hay también en esta historia de Roth y en todas sus otras novelas. Menocchio, por su parte proporciona argumentos de lecturas que han traspasado las membranas sociales y las ha recibido a su manera, como el Decamerón y la Biblia. Ambos personajes se nutren asimismo de la cultura oral de las clases populares europeas.

\section{Ideas religiosas y cosmogónicas}

Por lo dicho hasta ahora podemos decir que estos dos personajes son representativos de la religiosidad popular. Religión sin nombre de cristiano, budista o judío, sino un fenómeno cultural. Quizás en nuestro caso tienen en común el pertenecer a la tradición judeocristiana, que hunde sus raíces en creencias muy antiguas de grupos campesinos con aproximaciones telúricas y animistas a la naturaleza. Una religiosidad que traduce conceptos religiosos en conceptos morales propios.

En este sentido, nuestros dos personajes, aunque uno sea de ficción y el otro histórico, son seres activos, cuyas cabezas están siempre elaborando teorías. Activos y espontáneos porque su movimiento espiritual e intelectual surge de sus propias inclinaciones, no ha sido impuesto desde afuera. El movimiento se proyecta, asimismo, a otros aspectos de sus vidas. El vendedor de corales decide viajar hasta Odesa (lugar de origen del padre de Carlo Ginzburg. Nueva coincidencia) para conocer el mundo y comprobar sus teorías allí donde se supone habita el Leviatán que cuida a los corales: el mar.

Tanto Menocchio como el vendedor de corales son personajes de tragedia. El primero debe defender sus ideas frente a un tribunal y el segundo vive su 
propio juicio en el interior de su alma. El espíritu maligno tienta a Menocchio a llamar a la desobediencia. En el caso del vendedor de corales a dejar de cumplir las leyes del judaísmo y a vender su alma. En estos procesos, cada personaje es tentado, a su manera, a renunciar a sus ideas. En otra de las novelas de Roth -La Rebelión- Andreas Pum, un excombatiente de guerra termina en la cárcel por un pequeño incidente. Ahí acabará renegando de sus creencias religiosas y se convertirá en un rebelde, en una sociedad llena de crueldad, horror y corrupción (Roth La Rebelión). En Job, el protagonista Mendel Singer, quien es descrito al comienzo de la historia como un hombre "devoto, temeroso de Dios y normal y corriente, un judío como cualquier otro, termina perdiendo la fe. De Roth sabemos que él mismo estuvo tentado de vender su alma en su vida real. Su amigo Soma Morgensten ${ }^{4}$ nos relata algunos eventos de la vida de Joseph Roth en París, entre los que destaco aquí aquellos en que niega que es judío.

Si Menocchio se retracta puede salvar su vida. Si el vendedor cede a las tentaciones de un nuevo negocio reñido con los valores de la autenticidad, puede hacerse rico. El caso es que Menocchio será perseguido por sus ideas religiosas heterodoxas, mientras que los judíos, representados aquí en este vendedor de corales, huelen que se avecina el aniquilamiento total. Pero cada uno prefiere morir antes de renunciar a aquellas ideas alojadas en sus almas. El alcance de sus vidas y la épica de sus acciones permiten que el lector de cualquier parte del mundo se sienta identificado e incluso simpatice con las biografías de Menocchio y del vendedor de corales. En esto reside la universalidad de estas obras. Desde las historias pequeñas que se narran en la novela o la microhistoria que se explica desde la historiografía los personajes de ficción y de realidades, son capaces de cruzar fronteras de escalas para representar períodos y espacios más amplios que los propios. El objetivo de la microhistoria, que creo es extensible a lo que hace Roth en muchas de sus novelas, es utilizar la escala microscópica para ver cómo los fenómenos más grandes funcionan en escalas más pequeñas y cómo es que esos paradigmas de explicación a nivel más macro se experimentan en pequeñas escalas.

\section{Lo verdadero y lo ficticio}

La historia de Menocchio que hoy conocemos surge del trabajo minucioso de Carlo Ginzburg. La historia que nos relata Joseph Roth, en cambio es, -como diría Vargas Llosa- una mentira5. Esas mentiras creadas a propósito para contar una verdad que solo puede expresarse en forma disimulada. La ficción de Roth, como todas las otras ficciones, surge del descontento vital tanto personal como colectivo. Un malestar que llama imperiosamente a crear fórmulas para denunciar o para soñar. "No se escriben novelas para contar la vida, sino para transformarla". Esta mentira se nutre de la

4 Soma Morgenstern (Budzanów, Galitzia oriental, 1890-Nueva York, 1976), novelista, crítico y dramaturgo, fue amigo íntimo de Joseph Roth, con quien convivió algunos años en el París y la Viena de entreguerras. En su libro Huida y Fin de Joseph Roth relata la vida del escritor y el registro de una amistad.

5 Idea general del libro de Mario Vargas Llosa. La verdad de las Mentiras. Madrid: Editorial Alfaguara, 2002. 
experiencia humana y aquí es donde se puede acercar a las biografías de vida. La novela de Roth no nos habla de hombres de carne y hueso, sino de sus propias pequeñeces, añoranzas y miedos. Inventa personajes, escenarios e historias para sublimar las dificultades de su propia vida y de la época que le tocó vivir. Y entonces volvemos a citar a Vargas Llosa: las mentiras de las novelas no son nunca gratuitas, llenan las insuficiencias de la vida. Quizás de las opciones que hiciera Ginzburg de historiar a un hombre que fue sentenciado por sus ideas también se deduce su propia estrategia de llenar las insuficiencias de la vida. Por eso es que él intenta dar voz a los que no la han tenido en la historia, a los que han sido condenados por sus ideas. A los que como el molinero del Friuli y el vendedor de corales ruso, murieron sin renunciar a sus ideas.

Que surja esta idea de una relación interdisciplinaria entre Joseph Roth y Carlo Ginzburg no es algo tan descabellado. La de la literatura e historia ha sido una larga historia de encuentros y desencuentros. Como brillantemente ha expuesto Ivan Jablonka, quien incursionó en ambos géneros, el investigador se encuentra frente a una posibilidad de escritura y, por otra parte, una posibilidad de conocimiento se ofrece al escritor (Jablonka 11). El principal argumento del autor es que conciliar las ciencias sociales y la creación literaria "es intentar escribir de manera más libre, más justa, más original, más reflexiva, no para relajar la cientificidad de la investigación sino, al contrario, para fortalecerla" (Ibíd.).

Otro judío italiano -Claudio Magris- también reflexiona frente a las posibilidades de relación entre historia y literatura. Parte de un acontecimiento histórico para desarrollar su relato. La historia le permite volver atrás, a un pasado que se convierte en presente. "Y para el escritor, como para su protagonista, no se trata de buscar la verdad, sino de procurar buscar las explicaciones y las razones de una imitación de la verdad, anteponiendo la belleza de la verdad poética y de la sugerencia de la conjetura por encima de la verdad histórica" (ctd. en Magris 27).

Quisiera terminar este ensayo sin grandes conclusiones sino rindiendo honores al historiador que me hizo ver como posible, el ejercicio de buscar coincidencias, indicios y huellas para conjeturar posibles relaciones en este oficio de la historia.

\section{Obras citadas}

Anderson, Perry. "Pesquisa nocturna: Carlo Ginzburg". Secuencia 28 (1994): 191-216.

Burucua, Emilio, "Carlo Ginzburg: Una ratio individualizante y universal". Boletín de historia Social europea 2 (1990): 96-103.

Davis, Natalie. Regreso de Martin Guerre. Madrid: Akal, 2013.

Evans Restrepo, Michelle. "Lectura comparada de El Queso y los Gusanos de Carlo Ginzburg y la Herencia Inmaterial de Giovanni Levi". Historia y Sociedad 30 (2016): 105-129.

Ginzburg, Carlo. "Raíces de un paradigma de inferencias indiciales". Mitos, emblemas e indicios. Morfología e historia. Barcelona: Gedisa, 2008. 185-239. 
Ginzburg, Carlo. "Some Queries Addressed to Myself". Cromohs (Cyber Review of Modern Historiography) 18 (2013): 90-96.

Ginzburg, Carlo. El queso y los gusanos. Barcelona: Atajos, 1999.

Ginzburg, Carlo. "Microhistoria: Dos o tres cosas que sé de ella". Manuscrits 12 (1994): 13-42.

Jablonka, Iván. La historia es una literatura contemporánea. Manifiesto por las ciencias sociales. Buenos Aires: Fondo de Cultura de Económica, 2016.

Jiménez Becerra, Absalón. "Carlo Ginzburg: reflexiones sobre el método indiciario". Esfera 1: 1 (2011): 21-28.

Ladurie, Emmanuel Le Roy. Montaillou. Una aldea occitana. Madrid: Taurus, 1981.

Magris, Claudio. Lejos de dónde. Joseph Roth y la tradición hebraico-oriental. Pamplona: Ediciones Universidad de Navarra, 2013.

Morgenstern, Soma. Huida y fin de Joseph Roth. Valencia: Pre-Textos, 2008.

Roth, Joseph, Stefan Zweig, Madeleine Rietra y Rainer-Joachim Siegel, editores. Ser Amigo Mío Es Funesto: Correspondencia (1927-1938). Barcelona: Acantilado, 2014.

Roth, Joseph. La Rebelión. Barcelona: Acantilado, 2008.

Roth, Joseph. El Leviatán. Barcelona: Acantilado, 2013.

Roth, Joseph. Job. Barcelona: Acantilado, 2007

Stocke, Joy. "The Euphoria of Ignorance: Being Jewish, Becoming Jewish, The Paradox of Being Carlo Ginzburg" Wild River Review. 2013. New York Public Library. 2018 https://www.wildriverreview.com/columns/ live-from-the-nypl/euphoria-of-ignorance/. [Revisado 9/01/2018]

Vargas, Llosa. La verdad de las mentiras. Madrid: Alfaguara, 2002. 